\title{
Total energy expenditure and body composition in early infancy
}

\author{
J C K Wells, T J Cole, P S W Davies
}

\begin{abstract}
In adults greater energy expenditure, primarily on physical activity, is associated with greater leanness. Such an association has proved more difficult to demonstrate in infants, partly due to the difficulty of measuring fatness and free living energy expenditure in this age group. Stable isotope techniques now make such investigations more viable.

Objective-The relationship between body composition and energy expenditure was investigated in 12 week infants.

Methods-Total energy expenditure and fat mass were estimated using the doubly labelled water technique.

Subjects-92 normal healthy infants.

Results-Fat mass was correlated with both triceps and subscapular skinfold thicknesses $(\mathbf{p}<0.001)$. After controlling for body size, age was a significant predictor of fat mass $(p=0.003)$, whereas total energy expenditure was not $(p=0.463)$.

Conclusions-The cross sectional link between activity level and fatness in young infants, reported previously, does not persist when energy expenditure is considered.
\end{abstract}

(Arch Dis Child 1996;75:423-426)

Keywords: fat mass, energy balance, physical activity.

The energy balance equation, derived from the first law of thermodynamics, ${ }^{1}$ states that energy intake is equal to energy expended plus energy stored. In adults, changes in energy expenditure can alter body composition by affecting this balance, with physical activity being the most influential component of energy expenditure in normal healthy individuals. In healthy growing infants, energy balance is positive due to the deposition of energy in new tissue, but energy expenditure could still be related to the quantity of energy stored, especially energy deposited as fat.

However, a relationship between energy expenditure and body composition has been difficult to demonstrate in infants. A major reason for this is the fact that only recently have techniques for measuring energy expenditure in free living infants been developed. Before the application of the doubly labelled water method to infants, energy expenditure could be measured only in constrained conditions, such that the contribution of physical activity could not be included. Physical activity itself could only be assessed by methodologies such as simple actometers or observations, which were difficult to relate to energy expenditure. Similarly, estimates of body fatness in infancy were restricted to skinfold measurements or body mass index (BMI) which have been shown to be poor predictors of total body fatness in infancy. ${ }^{2}{ }^{3}$

Secondly, the balance between energy intake and expenditure is to some extent manipulated by the caregiver. A high level of infant weight gain was found to be associated with maternal perception of the infant as 'difficult', ${ }^{4}$ and it was suggested that such infants may be fed more to quieten them. ${ }^{4}$ More recently, data have been reported with respect to differences in the energy metabolism between breast fed and formula fed infants. ${ }^{5}$ Mean total energy expenditure was found to be significantly greater in the formula fed group, which also showed significantly greater mean energy deposition. The difference in energy deposition did not account for more than $25 \%$ of the greater energy expenditure. ${ }^{5}$ These studies indicate that in infants, greater energy expenditure may not necessarily be associated with lower levels of body fatness.

Thus the relationship between infant body composition and energy expenditure remains poorly understood. We have accordingly investigated this relationship in a large cross sectional study of infants aged 12 weeks.

\section{Subjects and methods}

A total of 100 infants was recruited from the Rosie Maternity Hospital, Cambridge, UK. All infants were healthy, born at term and had no known condition that might unduly influence health or development. At birth, infants were either exclusively breast fed or exclusively formula fed. However by 12 weeks of age, a small proportion of dietary energy intake was permitted to be supplied by supplementary foods. Ethical permission for the study was granted by Cambridge Health Authority and the Medical Research Council Dunn Nutrition Unit.

At or close to 12 weeks of age, a number of measurements were made over an eight day study period. Weight, supine length, and skinfold thicknesses at the triceps and subscapular sites were measured on the first day of the study period. Length and weight were also used to calculate BMI. Weight was measured again on the last day of the study period.

Body composition and total energy expenditure were measured by the doubly labelled water method, which has been described in detail elsewhere ${ }^{67}$ Briefly, the technique involves administration of two isotopic tracers, 
${ }^{2} \mathrm{H}$ and ${ }^{18} \mathrm{O}$, after which the dilution space and rate constant for each isotope is calculated. The ${ }^{18} \mathrm{O}$ dilution space can be used to calculate the size of the body water pool and hence, using a value for the water content of lean tissue, fat free mass. The difference in turnover rates of the two isotopes can be used to calculate carbon dioxide production, since the ${ }^{2} \mathrm{H}$ tracer is lost from the body as water, while the ${ }^{18} \mathrm{O}$ tracer is lost both as water and as carbon dioxide. Using an assumed respiratory quotient based on food quotient, ${ }^{8}$ carbon dioxide production can be used to predict oxygen consumption and hence, using Weir's equation, ${ }^{9}$ total energy expenditure (TEE). These methodologies have been successfully validated in studies of infants. ${ }^{10-12}$

In this study, the isotopes were administered orally either as water or added to approximately $10 \mathrm{ml}$ of made up formula milk. The dose was calculated according to the body weight of the infant, and was intended to give $0.28 \mathrm{~g}$ per kg body weight $\mathrm{H}_{2}{ }^{18} \mathrm{O}$ and $0.10 \mathrm{~g}$ per $\mathrm{kg}$ body weight ${ }^{2} \mathrm{H}_{2} 0$. A $1.5 \mathrm{ml}$ sample of the dosing mixture was retained for mass spectrometer analysis. The dosing apparatus was weighed accurate to two decimal places of a gram before and after dosing, allowing the quantity of dose given to be determined accurately. Urine samples were obtained from the infants before dosing and daily for the next seven days using the method of leaving cotton wool balls inside the nappy of the infant and, after urination, obtaining the urine sample by inserting the cotton wool in a syringe. ${ }^{13}$ The parents were asked to check the nappy frequently for urination, and the time of voiding was taken as the midpoint between the last two times of checking.

Urine samples and dosing mixtures were analysed using an Aqua-SIRA dual inlet mass spectrometer system for simultaneous analysis of ${ }^{18} \mathrm{O} /{ }^{16} \mathrm{O}$ and ${ }^{2} \mathrm{H} /{ }^{1} \mathrm{H}$ isotope ratios in water. Each sample was analysed nine times using consecutive $5 \mu \mathrm{l}$ injections in order to overcome memory effects in the mass spectrometer. Samples were also analysed in duplicate in order first of ascending and then of descending expected isotopic enrichment. Dilution spaces were calculated using the back extrapolation method. ${ }^{14}$ The fractionation factors were those used in the original experiments using the doubly labelled water technique, ${ }^{15}$ and the proportion of water subject to fractionation was taken to be $0.15 .^{16}$

Fat free mass (FFM) on day 1 of the study period was calculated from the ${ }^{18} \mathrm{O}$ dilution space and a value for the water content of lean tissue in 3 month infants. ${ }^{17}$ Fat mass was calculated as the difference between body weight and FFM.

Age, sex, FFM, and TEE were entered in a multiple regression equation with fat mass as the dependent variable.

\section{Results}

Characteristics of the infants are given in table 1. Successful doubly labelled water dosings were achieved in 92 of these infants. Unsuccessful dosings occurred when an unknown
Table 1 Characteristics of the infants at recruitment $(n=100)$

\begin{tabular}{ll}
\hline Mean (SD) gestational age (weeks) & $40.0(1.3)$ \\
Mean (SD) birth weight (g) & $3480(410)$ \\
Mean (SD) maternal age (years) & $29.9(5.1)$ \\
Male (\%) & 44 \\
Breast fed (\%) & 45 \\
Social class (No) & \\
I & 29 \\
II & 30 \\
III & 30 \\
IV & 6 \\
V & 5 \\
Parity (No) & \\
1 & 44 \\
2 & 33 \\
3 & 17 \\
4 & 5 \\
6 & 1 \\
\hline
\end{tabular}

quantity of dose was vomited or regurgitated by the infant within four hours of dosing. All subsequent tables refer to the 92 successfully dosed infants.

Age and anthropometric measurements are given in table 2 . Results of the doubly labelled water method are given in table 3. There were low but highly significant correlations between fat mass and triceps skinfold $(r=0.38$; p<0.001), subscapular skinfold $(r=0.36$; $\mathrm{p}<0.001)$ and BMI $(r=0.53 ; \mathrm{p}<0.001)$. Mean (SD) error of TEE measurement for the 92 infants was 5.1 (2.1)\%. Mean (SD) error of total body water measurement, calculated for a subset of 42 infants, was $2.1(0.9) \%$.

Results of the multiple regression equation are given in table 4. Age was the only predictor of fat mass to achieve statistical significance. No relationship between energy expenditure and fat mass was therefore apparent.

Table 2 Characteristics of infants on day 1 of the study $(n=92)$

\begin{tabular}{ll}
\hline & Mean (SD) \\
\hline Age (weeks) & $11.6(0.8)$ \\
Weight $(\mathrm{g})$ & $5890(600)$ \\
BMI $\left(\mathrm{kg} / \mathrm{m}^{2}\right)$ & $16.4(1.3)$ \\
Supine length (cm) & $59.9(2.1)$ \\
Triceps skinfold (mm) & $7.7(1.3)$ \\
Subscapular skinfold (mm) & $7.6(1.4)$ \\
\hline
\end{tabular}

Table 3 Results of doubly labelled water method ( $n=92)$

\begin{tabular}{ll}
\hline & Mean (SD) \\
\hline $\mathrm{N}_{\mathrm{o}}(\mathrm{ml})$ & $3541(377)$ \\
$\mathrm{N}_{\mathrm{d}}(\mathrm{ml})$ & $3674(395)$ \\
$\mathrm{k}_{\mathrm{o}}$ & $0.289(0.034)$ \\
$\mathrm{k}_{\mathrm{d}}$ & $0.245(0.031)$ \\
TBW (ml) & $3500(372)$ \\
Fat mass (kg) & $1.38(0.44)$ \\
FFM (kg) & $4.49(0.47)$ \\
TEE (kJ/day) & $1799(423)$
\end{tabular}

$N=$ dilution space, $k=$ rate constant for ${ }^{18} \mathrm{O}$ and ${ }^{2} \mathrm{H}$ respectively. TBW $=$ total body water.

Table 4 Results of multiple regression analysis of fat mass $(n=92)$

\begin{tabular}{llll}
\hline Variables & Coefficient & $S E$ & $p$ Value \\
\hline Age & 0.1668 & 0.0552 & 0.003 \\
Female sex & 0.0506 & 0.1048 & 0.630 \\
FFM & -0.1773 & 0.1188 & 0.139 \\
TEE & 0.0001 & 0.0001 & 0.463 \\
\hline
\end{tabular}




\section{Discussion}

Methodological difficulties have, until recently, limited the investigation of the role of energy balance on body composition in infants. Before the development of non-invasive means for measurement of TEE, energy expenditure in infants showing normal activity could not be measured. Instead, actometers attached to the wrist and ankle were used to provide a crude index of physical activity. ${ }^{18}$ A study of physical activity assessed by actometers and subcutaneous fatness in 31 infants aged 4-6 months found that in infants within 1SD of mean triceps skinfold thickness, physical activity did not correlate significantly with fatness, indicating that energy intake was efficiently balanced against energy expenditure. ${ }^{18}$ However, in very thin or very fat infants, there was a high negative correlation between activity and fatness. Thus the lean infants were active and the fat infants inactive. ${ }^{18}$

A similar study on five infants aged 1-8 weeks also found an inverse relationship between activity level and weight gain. ${ }^{19} \mathrm{How}-$ ever in this study no adjustment was made by the authors for gain in length, and if the data on weight gain and length gain from their study are entered in the regression equation together, length gain is a much stronger predictor of activity level. It was therefore the taller infants in this study who were more active, which may be due to the effects of limb length on actometer readings. Moreover, both these studies assessed fatness through measurements of skinfold thicknesses, which provide an estimate of subcutaneous fatness rather than of total body fatness.

A more recent longitudinal study of 31 infants investigated the relationship between activity and body fatness at 6,9 , and 12 months. ${ }^{20}$ Fatness was measured by dual $x$ ray absorbtiometry, and activity by direct observation. Fatness and activity level were inversely related at each time point. However, while early activity was a poor predictor of later fatness, early fatness was a good predictor of later activity level. ${ }^{20}$

In our study we have attempted to utilise accurate measures of fatness and energy expenditure in a much larger sample of infants. Mean weight and length of our sample indicate that the infants were representative of the contemporary British population. ${ }^{21}{ }^{22}$ Mean fatness is similar to that described for the reference infant. ${ }^{17}$ Mean TEE is similar to that reported from another study of infants of this age. ${ }^{23}$ The relatively low correlation between subcutaneous fatness and total body fatness has been reported previously and is likely to arise as a consequence of variation in the distribution of internal and external fat stores. ${ }^{3}$

There was a significant relationship between percentage fatness and sex, with girls being fatter, but not between fat mass and sex. This can be explained by the greater FFM of the boys, and is consistent with values reported from other studies on infants of this age. ${ }^{172}$ The relationship between fatness and age, with older infants being fatter, has also been reported previously. ${ }^{1724}$ The increase in per- centage fat is rapid in the first few months of life, ${ }^{24}$ so that the effect was apparent even in our narrow age range.

Multiple regression analysis showed no relationship between fat mass and TEE. It is increasingly realised that apparent associations between level of energy expenditure and body fatness may be created by inherent mathematical bias in the relationship between metabolism and body size. ${ }^{25-27}$ For example, dividing energy expenditure by body weight does not fully adjust energy expenditure for size. ${ }^{28}$ The quantity energy expenditure/ $\mathrm{kg}$ is therefore not mass independent, and is still related to body size. There are two solutions to this problemeither dividing energy expenditure by body size raised to a certain power, which is determined from a separate analysis, ${ }^{28}$ or adjusting for body size by regression analysis as in the present study.

It is also important to select an appropriate index when adjusting for body size. In the present study, for example, if weight rather than FFM is the variable used to adjust TEE for body size, a link between TEE and fat mass is found. However, this association is an artefact of the relationship $(r=0.63)$ between weight and fat mass, which is therefore present on both sides of the regression equation. For similar reasons, our regression used fat mass as the dependent variable, rather than percentage fat which should not be regarded as a mass independent variable.

Thus the relationship between physical activity and body fatness in infants, reported previously, ${ }^{18-20}$ could not be demonstrated in the present study in terms of energy expenditure. The previous studies on younger infants assessed activity in terms of physical movement, using actometers. ${ }^{1819}$ However, in a study comparing behaviour with activity energy expenditure in 12 week infants, sleeping and infant mood were found to be the best predictors of activity energy expenditure. ${ }^{29}$ Thus motor movement may be a poor index of daily activity energy expenditure in infants not yet mobile.

Nevertheless, physical activity may play an indirect part in the persistence of infant fatness into childhood. In older infants, activity level did not predict subsequent fatness, but fatness did predict subsequent activity level..$^{20}$ Likewise, in a subset of the infants described in the present study, infant energy expenditure and behaviour did not predict later body fatness, but infant fatness did predict behavioural activity in early childhood. ${ }^{30}$ It is therefore possible that, over time, greater infant fatness restricts activity level and thereby influences energy balance.

1 Helmholtz $\mathrm{H}$ von. Uber die Erhaltung der Kraft. Berlin: G Reiner, 1847

2 Davies PSW, Lucas A. Quetelet's index as a measure of fatness in young infants. Early Hum Dev 1989;20:135-41.

3 Davies PSW, Lucas A. The prediction of body fatness in early infancy. Early Hum Dev 1989;21:193-8.

4 Carey WB. Temperament and increased weight gain in infants. Developmental and Behavioral Pediatrics 1985;6: 128-31.

5 Davies PSW, Ewing G, Coward WA, Lucas A. Energy metabolism in breast-fed and formula-fed infants. In: Atkinson SA, Hanson LA, Chandra RK, eds. Breastfeeding, nutrition, infection and infant growth in developed and 
emerging countries. St John's, Newfoundland: Arts Biomedical, 1990:521.

6 Coward WA. The doubly-labelled water $\left({ }^{2} \mathrm{H}_{2}{ }^{18} \mathrm{O}\right)$ method: principles and pracatice. Proc Nutr Soc 1988;47:209-18.

7 Davies PSW, Ewing G, Lucas A. Energy expenditure in early infancy. Br F Nutr 1989;62:621-9.

8 Black AE, Prentice AM, Coward WA. Use of food quotients to predict respiratory quotients for the doubly labelled water method of measuring energy expenditure. Hum Nutr:Clin Nutr 1986;40C:381-91.

9 Weir JB de. New methods for calculating metabolic rate with special reference to protein metabolism. F Physiol 1949, 109:1-9.

10 Roberts SB, Coward WA, Schingenseipen $\mathrm{KH}$, Nohria V, Lucas A. Comparison of the doubly labeled water $\left({ }^{2} \mathrm{H}_{2}{ }^{18} \mathrm{O}\right)$ method with indirect calorimetry and a nutrient balance study for simultaneous determination of energy expenditure, water intake, and metabolisable energy intake in preture, water intake, and metabolisable energy inta
term infants. Am $₹$ Clin Nutr 1986;44:315-22.

11 Jones PJH, Winthrop AL, Schoeller DA, et al. Validation of doubly labeled water for assessing energy expenditure in infants. Pediatr Res 1987;21:242-6.

12 Jensen CL, Butte NF, Wong WW, Moon JK. Determining ${ }^{2} \mathrm{H}_{2}{ }^{18} \mathrm{O}$ method and indirect calorimetry. $\mathrm{Am} \mathcal{F}$ Physio 1992;263:R685-92.

13 Roberts SB, Lucas A. Measurement of urinary constituents and output using disposable napkins. Arch Dis Child 1985; 60:1021-4.

14 Davies PSW, Wells JCK. Calculation of total body water in infancy. Eur f Clin Nutr 1994;48:490-5.

15 Lifson N, Gordon GB, McClintock R. Measurement of total carbon dioxide production by means of $\mathrm{D}_{2}{ }^{18} \mathrm{O} . \mathcal{f} A \mathrm{ppl}$ Physiol 1955;7:704-10.

16 Vasquez-Velasquez L. Energy expenditure and physical activity of malnourished Gambian infants. Proc Nutr Soc 1988;47:233-9.

17 Fomon SJ, Haschke F, Ziegler EE, Nelson SE. Body composition of reference children from birth to age 10 years. Am $\mathcal{F}$ Clin Nutr 1982;35:1169-75.
18 Rose H, Mayer J. Activity, calorie intake, fat storage and the energy balance of infants. Pediatrics 1968;41:18-29.

19 Mack RW, Kleinhenz ME. Growth, caloric intake, and activity levels in early infancy: a preliminary report. Hum Biol 1974;46:345-54.

$20 \mathrm{Li} \mathrm{R}$, O'Connor L, Buckley D, Specker B. Relation of activity levels to body fat in infants 6 to 12 months of age. $\mathcal{J}$ Pediatr 1995;126:353-7.

21 Tanner JM, Whitehouse RH, Takaishi M. Standards from birth to maturity for height, weight, height velocity and weight velocity: British children, 1965; Part II. Arch Dis Child 1966;41:613-35.

22 Freeman JV, Cole TJ, Chinn S, Jones PRM, White EM, Preece MA. Cross sectional stature and weight reference curves for the UK, 1990. Arch Dis Child 1995;73:17-24.

23 Roberts SB, Savage J, Coward WA, Chew B, Lucas A Energy expenditure and intake in infants born to lean and Energy expenditure and intake in infants born to lean

24 Davies PSW. Estimates of total body fatness in infancy and childhood. Am $\mathcal{F}$ Hum Biol 1992;4:621-4.

25 Goran MI, Carpenter WH, McGloin A, Johnson R, Hardin JM, Weinsier RL. Energy expenditure in children of lean and obese parents. Am F Physiol 1995;268:E917-24.

26 Carpenter WH, Poehlman ET, O'Connell M, Goran MI Influence of body composition and resting metabolic rate on variation in total energy expenditure: a meta-analysis. Am $\mathcal{F}$ Clin Nutr 1995;61:4-10.

27 Prentice AM, Black AE, Coward WA, Cole TJ. Energy expenditure in overweight and obese adults in affluent ments. Eur 7 Clin Nutr 1996;50:93-7.

28 Wells JCK, Davies PSW. Sleeping metabolic rate and body size in 12-week-old infants. Eur $\mathcal{f}$ Clin Nutr 1995;49:323-8.

29 Wells JCK, Davies PSW. The relationship between behaviour and energy expenditure in 12 week infants. Am $\mathfrak{f}$ Hum iour and energy exp

30 Wells JCK, Stanley M, Laidlaw AS, Day JME, Davies PSW. The relationship between components of infant energy expenditure and childhood body fatness. Int $\mathcal{f}$ Obes 1996;20:848-53. 